\title{
Lumbar Epidural Varix Mimicking Disc Herniation
}

\author{
Adem Bursalı, M.D., ${ }^{1}$ Goktug Akyoldas, M.D., ${ }^{2}$ Ahmet Burak Guvenal, M.D., ${ }^{1}$ Onur Yaman, M.D. ${ }^{3}$ \\ Department of Neurosurgery, ${ }^{1}$ Ballkesir State Hospital, Ballkesir, Turkey \\ Department of Neurosurgery, ${ }^{2}$ Kent Hospital, Izmir, Turkey \\ Department of Neurosurgery, ${ }^{3}$ Koc University, Istanbul, Turkey
}

\begin{abstract}
Lumbar radiculopathy is generally caused by such well-recognized entity as lumbar disc herniation in neurosurgical practice; however rare pathologies such as thrombosed epidural varix may mimic them by causing radicular symptoms. In this case report, we present a 26-year-old man with the complaint of back and right leg pain who was operated for right L4-5 disc herniation. The lesion interpreted as an extruded disc herniation preoperatively was found to be a thrombosed epidural varix compressing the nerve root preoperatively. The nerve root was decompressed by shrinking the lesion with bipolar thermocoagulation and excision. The patient's complaints disappeared in the postoperative period. Thrombosed lumbar epidural varices may mimic lumbar disc herniations both radiologically and clinically. Therefore, must be kept in mind in the differential diagnosis of lumbar disc herniations. Microsurgical techniques are mandatory for the treatment of these pathologies and decompression with thermocoagulation and excision is an efficient method.
\end{abstract}

Key Words : Epidural $\cdot$ Lumbar $\cdot$ Radiculopathy $\cdot$ Varix $\cdot$ Venous plexus.

\section{INTRODUCTION}

Patients who have lumbar disc herniation presenting with low back and leg pain are the most common cases that we see in our neurosurgery practice. Lumbar epidural varices may mimic lumbar disc herniation by causing radiculopathy ${ }^{2,13)}$. In various publications, the incidence rate of lumbar epidural varices was reported as $0.067-1.2 \%{ }^{6}$. The diagnosis of this entity is usually made intraoperatively. In this publication, we now report a patient of lumbar epidural varix presented with radiculopathy symptoms and mimicked a lumbar disc herniation.

\section{CASE REPORT}

A 26-years-old male patient presented to our neurosurgery department with low back and severe right leg pain. His pain has originated in the lower back and spread to the heel. He was healthy otherwise. He did not benefit from bed rest and conservative treatments. Lasègue's sign was positive and loss of sensation in L5 dermatome was noted during the neurological examination. There was no motor deficit. Lumbosacral MRI scan showed a lesion in the epidural space at the upper L5 level just posterior to L5 vertebra on the right appearing as hypointense on the T1-weighted images and hyperintense on the T2-weighted images (Fig. 1, 2). The MRI reported as herniated nucleus pulposus. We decided to perform surgery with a diagnosis of L4-5 disc herniation. Right L4-5 hemilaminectomy was performed. After removal of the flavum, L5 foraminotomy was performed. A well shaped, brown mass lesion, which compressed the right L5 nerve root was identified during surgery. The mass was in connection with the epidural venous plexus. It was dissected from neighbor structures and a puncture was done by purified protein derivative (PPD) needle and it was understood that the epidural lesion was thrombosed varicose vein. The mass lesion lost its volume after bipolar thermocoagulation and was removed after cutting the connections with epidural plexus. The removal of the lesion decompressed the dural sac and root. Exploration revealed no evidence of a disc herniation, therefore, L4-5 discectomy was not performed. The pathological examination of the lesion showed dilated and tortuous vessels and the final diagnosis was epidural varix (Fig. 3). On postoperative day 1 , progressive physical therapy was started. His postoperative course was unremarkable. After surgery, the varix wasn't observed on the postoperative MRI scan (Fig. 4). His

- Received : June 19, 2015 • Revised : December 7, 2015 •Accepted : December 10, 2015

- Address for reprints : Goktug Akyoldas, M.D.

Department of Neurosurgery, Kent Hospital, 8229/1 Sokak № : 5635630 Cigli-lzmir, Turkey

Tel : +90-5066892909, Fax : +90-2323767071, E-mail : goktug_akyoldas@hotmail.com

- This is an Open Access article distributed under the terms of the Creative Commons Attribution Non-Commercial License (http://creativecommons.org/licenses/by-nc/3.0) which permits unrestricted non-commercial use, distribution, and reproduction in any medium, provided the original work is properly cited. 

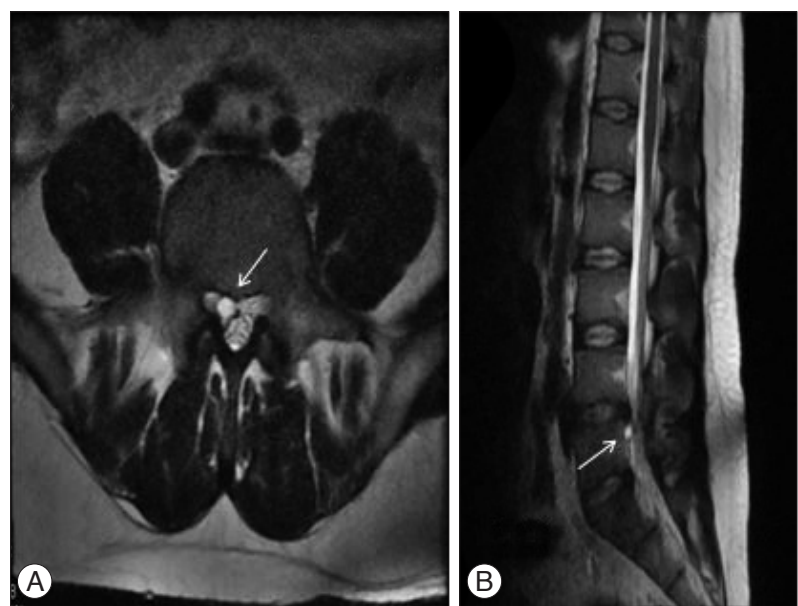

Fig. 1. Preoperative T2-axial (A) and T2-sagittal (B) magnetic resonance imaging show hyperintense lesions compressing the right spinal root. The white arrow shows the lesion.

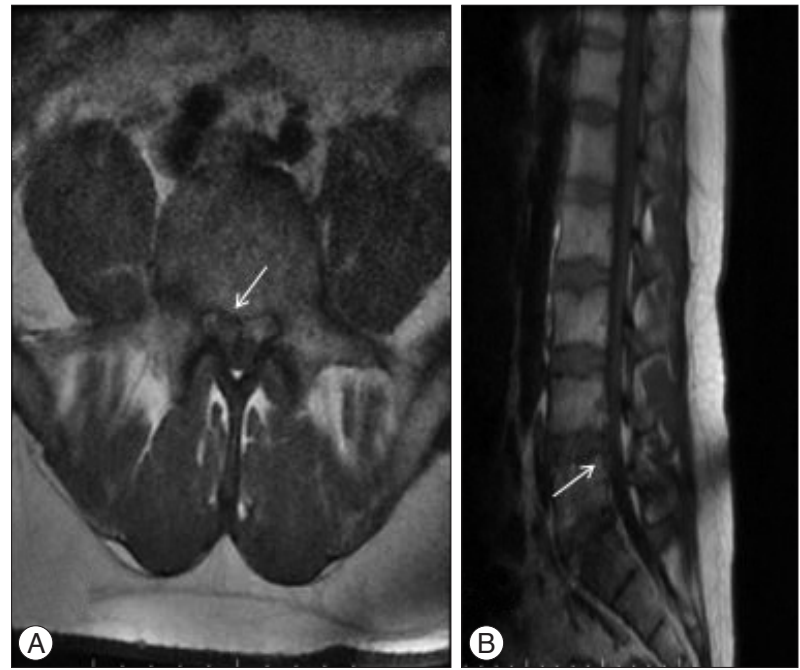

Fig. 2. Preoperative T1-axial (A) and T1-sagittal (B) magnetic resonance imaging show hypointense lesions compressing the right spinal root. The white arrow shows the lesion.

symptoms resolved, and he was discharged on day 2 . In first month control, no neurological symptoms and findings were observed.

\section{DISCUSSION}

The spinal venous system is a valveless large network that communicates with the inferior vena cava, the pelvic veins and the azygous system. Enlargement of the anterior internal vertebral vein and the radicular veins which are part of the spinal venous system transversing the intervertebral foramen with nerve root usually causes root compression ${ }^{14)}$. Mechanism of the lumbar varix is exactly unknown, but increased venous pressure due to the blockage of blood flowing through to vena cava system is thought as the main reason. Therefore, Paksoy and Gormus ${ }^{11)}$ reported that increased intrathoracic or intra-abdominal

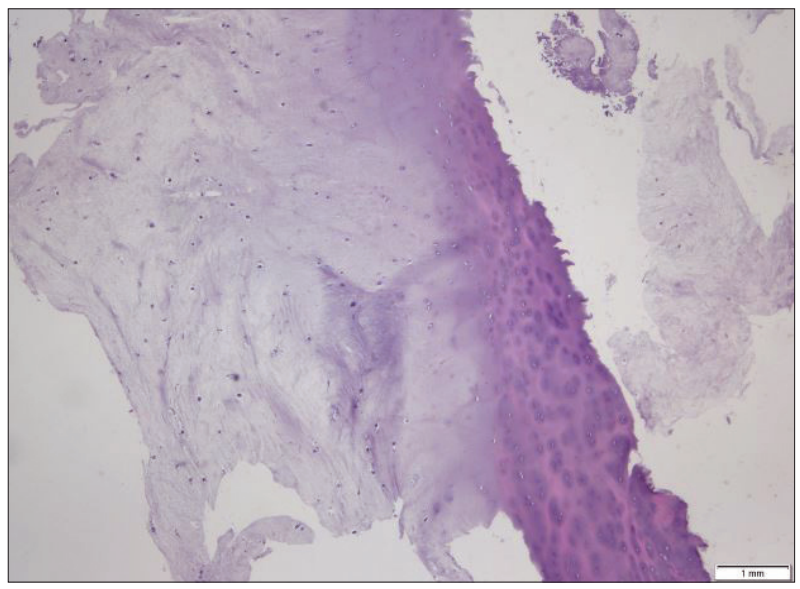

Fig. 3. In the pathological examination, large and tortuous vessels were seen $(H \& E, \times 200)$.

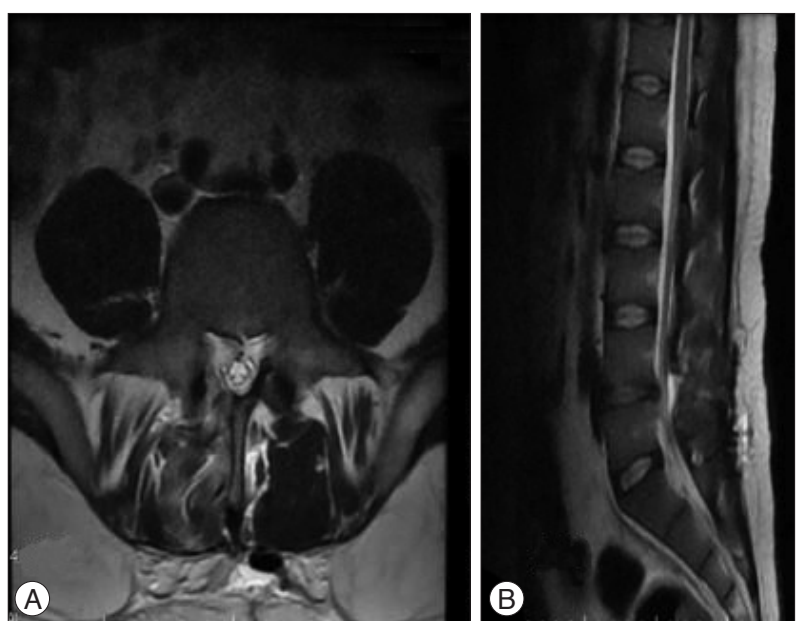

Fig. 4. Postoperative $T 2$-axial (A) and T2-sagittal (B) magnetic resonance slices show the absence of the lesion.

pressure (e.g., large masses, pregnancy) can lead to obstruction of the inferior vena cava; major congestion and vessel enlargement within the spinal canal subsequently cause radiculopathy and low back pain. In the study of Campbell et al. ${ }^{4}$, increased intra-abdominal pressure in obese and pregnant patients may constitute lumbar radiculopathy due to epidural varices. In both studies, when pressure on the inferior vena cava was removed, a decrease in pain intensity and radiculopathy symptoms was observed. Local factors such as herniated disc also play a role in the etiology of venous varix by causing compression. Disc herniations may cause endothelial injury, resulting in thrombotic occlusion of the anterior longitudinal veins. This is the main reason for the mechanism of the symptomatic lumbar epidural varices associated with large foraminal and central disc herniations $^{16)}$. If there are an epidural fibrosis and attached epidural veins to the posterior longitudinal ligament (PLL), large herniated nucleus pulposus and rupture of the PLL may cause rupture of varicose veins due to hematoma and varicosity. These venous dilatations cause radiculopathy symptoms ${ }^{1)}$. In many 
reports, lumbar varices have been found in association with spinal stenosis, spondyloarthropathy and ankylosing spondylitis. In these pathologies, it was difficult to make a differential diagnosis ${ }^{7)}$. Hanley et al. ${ }^{8)}$ divided the spinal epidural various veins into 3 types according to MRI findings. Type 1 is thrombosed dilated epidural veins, type 2 is epidural vein dilation without thrombosis and type 3 is submembranous epidural-contained hematoma. Hanley et al. have used MRI findings for their classification. MRI may help in the diagnosis of thrombosed epidural veins. Though thrombosed varices are often seen hyperintense on T1-weighted and T2-weighted images, they can be seen hypointensity on T2-weighted MRI sequences according to the intensity of the thrombosis ${ }^{10)}$. Due to the amount of water they contain, lumbar disc herniations are seen hypo- and hyperintensity on MRI sequences. Therefore, lumbar epidural varices mimic as a lumbar disc herniation on MRI. In our case, the thrombosed epidural veins were hypointense in sagittal T1weighted MRI slices and hyperintense in sagittal and axial T2weighted MRI slices. The lesion was reported as a herniated disc on lumbar MRI study. When MRI scan has been found to be insufficient, spinal angiography or venography can help in the diagnosis. However, thrombosed lumbar epidural varices usually can be diagnosed intraoperatively ${ }^{12}$. Besides a number of vascular structures and pathologies such as spinal arteriovenous hemangioma and lumbar abscess may mimic disc herniation $^{3,9)}$. The proper evaluation of the preoperatively radiological findings is very important for the exact diagnosis. Surgery is the best treatment for the symptomatic spinal epidural varices ${ }^{5)}$. The use of surgical microscopes and microsurgical techniques for accurate diagnosis and treatment has been standardized. Surgical technique should be selected according to the type of varix and patient's clinical manifestations. The goals of the surgery should be the decompression of the dural sac and/or spinal nerve roots, and elimination of dilated veins' irritation. Acceptable results have been reported after surgical thermocoagulation, laminectomy, excision or partial excision in the treatment of spinal epidural varices ${ }^{14)}$. Surgical excision also provides pathological diagnosis exactly. However, it is unnecessary to excise varix, if the other surgical methods are expected to relieve the clinical findings. In cases of large varices, wide laminectomy or wide hemilaminectomy with medial facetectomy provide higher visibility of venous structures, but in cases of local varices, the nerve roots and varicose intervertebral veins may be exposed by a limited laminotomy and medial facetectomy. When there was bilateral lumbar radiculopathy, a bilateral laminotomy or laminectomy can be performed ${ }^{14)}$. Intraoperatively, massive bleeding from abnormal dilated venous plexus can occur ${ }^{15}$. If coagulation is applied at a greater degree, it can not only cause considerable blood flow change but also rupture of the dilated vein. When the vein contracts under thermocoagulation, it can be cut in the coagulated zone. Therefore, coagulation does not cause tension of the epidural veins ${ }^{14)}$. In our case, the varicose vein was totally occluded and removed after cutting the con- nections with associated epidural veins. After removal of the varix, the decompression of the spinal root and dural sac was observed. The patient clinically improved after surgical removal of the spinal epidural vein. At the first month, the absence of the varix was observed on the postoperative MRI scan. By means of these findings, we believe that thermocoagulation and total or partial excision of lumbar epidural varices, which compress the nerve roots, are effective surgical methods in the treatment.

\section{CONCLUSION}

Symptomatic lumbar epidural varices are rare entities and usually clinically and radiologically mimic lumbar disc herniation. Spinal epidural varices should be kept in mind in the differential diagnosis of the lumbar disc herniation. In most cases, the lesion has been diagnosed only at surgery. Bipolar thermocoagulation and total or partial excision produce considerable long-term results. Our case highlights the need to be aware of enlargement of an epidural vein as a potential source of radiculopathy when surgery is being planned for a presumed lumbar disc herniation.

\section{References}

1. Akutsu H, Sugita K, Sonobe M, Matsumura A : A case of nontraumatic spinal epidural hematoma caused by extradural varix : consideration of etiology. Spine J 3 : 534-538, 2003

2. Aoyama T, Hida K, Akino M, Yano S, Saito H, Iwasaki Y : Radiculopathy caused by lumbar epidural venous varix : case report. Neurol Med Chir (Tokyo) $48: 367-371,2008$

3. Bakar B, Tekkok IH : Lumbar periradicular abscess mimicking a fragmented lumbar disc herniation : an unusual case. J Korean Neurosurg Soc 44 : 385-388, 2008

4. Campbell DN, Liechty RD, Rutherford RB : Traumatic thrombosis of the inferior vena cava. J Trauma $21: 413-415,1981$

5. Dickman CA, Zabramski JM, Sonntag VK, Coons S : Myelopathy due to epidural varicose veins of the cervicothoracic junction. Case report. J Neurosurg 69 : 940-941, 1988

6. Endres $S$ : Epidural varicosis as a possible cause of radicular pain : a case report. J Med Case Rep $5:$ 537, 2011

7. Genevay S, Palazzo E, Huten D, Fossati P, Meyer O : Lumboradiculopathy due to epidural varices : two case reports and a review of the literature. Joint Bone Spine 69 : 214-217, 2002

8. Hanley EN Jr, Howard BH, Brigham CD, Chapman TM, Guilford WB, Coumas JM : Lumbar epidural varix as a cause of radiculopathy. Spine (Phila Pa 1976) $19:$ :2122-2126, 1994

9. Kim KH, Song SW, Lee SE, Lee SH : Spinal epidural arteriovenous hemangioma mimicking lumbar disc herniation. J Korean Neurosurg Soc 52 : 407-409, 2012

10. Lee YS, Choi ES, Kim JO, Ji JH : A rare calcified thrombosis of the dilated epidural venous plexus presenting with lumbar radiculopathy : a case report. Spine J 11 : e28-e31, 2011

11. Paksoy Y, Gormus N : Epidural venous plexus enlargements presenting with radiculopathy and back pain in patients with inferior vena cava obstruction or occlusion. Spine (Phila Pa 1976) 29 : 2419-2424, 2004

12. Pekindil G, Yalniz E : Symptomatic lumbar foraminal epidural varix. Case report and review of the literature. Br J Neurosurg 11 : 159-160, 
1997

13. Pennekamp PH, Gemünd M, Kraft CN, von Engelhardt LV, Lüring C, Schmitz A : [Epidural varicosis as a rare cause of acute radiculopathy with complete foot paresis--case report and literature review]. Z Orthop Ihre Grenzgeb 145 : 55-60, 2007

14. Slin'ko EI, Al-Qashqish II : Surgical treatment of lumbar epidural vari- ces. J Neurosurg Spine 5 : 414-423, 2006

15. Wong CH, Thng PL, Thoo FL, Low CO : Symptomatic spinal epidural varices presenting with nerve impingement : report of two cases and review of the literature. Spine (Phila Pa 1976) 28 : E347-E350, 2003

16. Zimmerman FA, Weingarten K, Lavyne MH : Symptomatic lumber epidural varices. Report of two cases. J Neurosurg 80 : 914-918, 1994 